\title{
Percutaneous Ultrasound-Guided Renal Biopsy in Children: The Need for Renal Biopsy in Pediatric Patients with Persistent Asymptomatic Microscopic Hematuria
}

\author{
Mei-Ching Yu ${ }^{1}$, Fan Lee ${ }^{2}$, Wen-Hung Huang ${ }^{3}$, Swei Hsueh ${ }^{4}$
}

Background: Percutaneous renal biopsy (PRB) is essential for the diagnosis, prognosis, and management of children with unknown kidney disease. In this study, the safety and efficacy of PRB is investigated, and also the common etiologies of childhood kidney disease, based on histological findings. In addition, we explored the role of PRBs in the diagnosis of children who presented with persistent asymptomatic hematuria.

Methods: $\quad$ By chart review, from July 2005 to July 2009, a total of 99 PRBs were performed on 91 children (43 girls and 48 boys; mean age, $10.9 \pm 4.4$ years) under ultrasound (US) guidance, by a doctor, using an automated 18-gauge biopsy needle following the same protocol, at a medical center in northern Taiwan.

Results: The accuracy of the histological diagnosis was excellent. The most common post-biopsy complications were perirenal hematoma $(11.1 \%)$ and asymptomatic gross hematuria $(3.0 \%)$, respectively. Nevertheless, these complications resolved spontaneously, and none had major bleeding episodes. Histological results showed that lupus nephritis, minimal change disease, and $\operatorname{Ig}$ A nephropathy (IgAN) could be the current leading causes of childhood kidney diseases in Taiwan.

Conclusions: Automated ultrasound (US)-guided PRB is a safe and reliable method of assessing childhood renal disease. A recent study shows that the presence of persistent asymptomatic isolated microhematuria in adolescents is a predictive marker of future end-stage renal disease. Hence, the emphasis of renal biopsy on children with persistent asymptomatic hematuria is beneficial for the early diagnosis of IgAN or other glomerulonephritis (GN), which tends toward progressive kidney disease in adulthood without prompt therapeutic intervention.

(Biomed J 2014;37:391-397)

Key words: IgA nephropathy, percutaneous renal biopsy, persistent hematuria

\section{INTRODUCTION}

$\mathrm{P}$ ercutaneous renal biopsy (PRB) is an important diagnostic tool used to obtain renal cortical tissues for

\section{At a Glance Commentary \\ Scientific background of the subject}

Automated US-guided PRB is the safe and reliable method of either disease diagnosis or prognosis. Pathologically, MCD, LN and IgAN are possibly the most common childhood kidney disorders in Taiwan.

\section{What this study adds to the field}

In addition to renal involvement secondary to SLE, IgAN is probably the leading primary GN underlined Taiwanese children with persistently asymptomatic hematuria with/without proteinuria. Since persistent microscopic hematuria is supposed to be the risk factor associated with future renal failure, the consideration of renal biopsy among these affected children is needed to be highlighted for early diagnosis of IgAN and other severe GN.

From the 'Department of Pediatric Nephrology, Chang Gung Children's Hospital at Linkou, Chang Gung University College of Medicine, Taoyuan, Taiwan; ${ }^{2}$ Department of Nephrology, Yee Zen General Hospital, Taoyuan, Taiwan; ${ }^{3}$ Department of Nephrology, Chang Gung Memorial Hospital at Linkou, Chang Gung University College of Medicine, Taoyuan, Taiwan; ${ }^{4}$ Department of Anatomic Pathology, Chang Gung Memorial Hospital at Linkou, Chang Gung University College of Medicine, Taoyuan, Taiwan Received: Sep. 25, 2012; Accepted: Dec. 12, 2013

Correspondence to: Dr. Mei-Ching Yu, Department of Pediatric Nephrology, Chang Gung Children's Hospital at Linkou. 5 Fusing St., Gueishan, Taoyuan 333, Taiwan (ROC). Tel: 886-3-3281200 ext. 8206; Fax: 886-3-3288957; E-mail: yumeiching@ gmail.com

DOI: $10.4103 / 2319-4170.132878$ 
introduction of real-time ultrasound (US) guidance and the invention of automated biopsy instruments make this technique more feasible, efficient, and less risky. ${ }^{[1-4]}$ Previous literature has revealed that the overall biopsy-related complication rate in pediatric patients is around 5-23\%. ${ }^{[2,5-8]}$ The majority developed minor bleeding complications post-PRB, including macroscopic hematuria (3-10\%) and perirenal hematoma (12-42\%). ${ }^{[1,5-8]}$ However, some still suffered severe major bleeding complications $(0.8-7 \%)$ necessitating blood transfusion or emergent surgical intervention. ${ }^{[1,7,9,10]}$ On the other hand, the procedures and biopsy instruments are similar for both adults and children, but some technical modifications are needed to suit children ${ }^{[6,8,11]}$ For instance, no food intake is suggested prior to pediatric biopsies, so as to minimize the danger of choking caused by vomiting during the procedure. Additionally, the administration of a general anesthetics plus sedatives is recommended for uncooperative young children, where it is deemed to be too risky to perform renal biopsy. In our practice, a combination of ketamine and midazolam used to be prescribed for children younger than 10 years of age, whereas only local analgesia was given to children older than 10 years of age. In the present study, the aim was to investigate the safety and efficiency of pediatric PRB. Meanwhile, we also evaluated the patterns of childhood renal disease in Taiwan, based on the histological features.

\section{METHODS}

From July 2005 to July 2009, we retrospectively reviewed the medical records of 99 consecutive native PRBs performed on 91 children, consisting of 43 girls (mean age, $11.6 \pm 4.3$ years) and 48 boys (mean age, $10.2 \pm 4.4$ years), in the Pediatric Nephrology Unit of the Chang Gung Children's Hospital, Linkou Medical Center, in Taiwan. Patients who presented with abnormal urinalysis such as proteinuria \pm hematuria, persistent asymptomatic isolated hematuria or unexplained renal function impairment were identified for PRBs [Table 1]. Of 91 biopsied children, five cases with lupus nephritis (LN) and one with $\operatorname{Ig}$ A nephropathy (IgAN) received PRBs twice, and a boy who was diagnosed with post-infectious glomerulonephritis received PRBs thrice for guiding clinical treatments and determining the outcome. Comprehensive medical histories, laboratory and physical examinations, and image studies (US and intravenous pyelogram or computed tomography (CT) were implemented preceding renal biopsy. Structural abnormalities such as the nutcracker syndrome, hydronephrosis, urolithiasis, renal tumor, and hypercalciuria were excluded in all cases. All PRBs were conducted by the same pediatric nephrologist, with an automated 18-gauge needle gun, under US guidance.
Table 1: Indications for PRBs in 91 children

\begin{tabular}{lc}
\hline Indication & No. of patients $(\%)$ \\
\hline $\begin{array}{l}\text { SLE with renal involvement } \\
\text { Nephrotic syndrome }\end{array}$ & $32(35.2)$ \\
$\quad \begin{array}{l}\text { Frequent relapsing steroid } \\
\text { dependent }\end{array}$ & $12(13.2)$ \\
$\quad$ Steroid-resistant & $3(3.3)$ \\
Age-related (<1 year or $>10$ years) & $12(13.2)$ \\
Persistent hematuria with & $18(19.8)$ \\
mild-to-heavy proteinuria* & \\
Persistent isolated hematuria & \\
Unexplained renal failure & $4(4.4)$ \\
Isolated proteinuria & $9(9.9)$ \\
Total & $1(1.0)$ \\
${ }^{*}$ Mild to heavy proteinuria ranging between 100 and $500 \mathrm{mg} / \mathrm{dl} ;$ \\
${ }^{\dagger}$ Asymptomatic isolated hematuria was defined as more than $20 \mathrm{RBCs} / \mathrm{uL}$ \\
in urine with undetectable proteinuria
\end{tabular}

\section{Pre-renal biopsy preparation}

Written informed consent was obtained from the parents or legal guardians prior to the renal biopsy. Detailed family and personal medical histories were taken, with an emphasis on histories of hereditary bleeding disorders or use of particular drugs such as aspirin, dipyridamole or warfarin, which are known to increase the risk of prolonged bleeding. Additionally, children who had significant hypertension were avoided until they had been treated adequately. Initial laboratory examinations included serum creatinine (Scr), blood urea nitrogen, electrolytes, hemoglobulin concentration, platelet count, prothrombin time, activated partial thromboplastin time, bleeding time, and urinalysis. Coagulopathy was absolutely contraindicated for PRB. Renal biopsy could be not considered until it was corrected by transfusion of fresh frozen plasma or platelets. Once prolonged bleeding time, equal to or greater 10 minutes, was found in patients with renal dysfunction, the administration of a cryoprecipitate was recommended, and repeats were necessary to ensure that the abnormal bleeding tendency was corrected.

\section{Renal biopsy procedure}

A general anesthetic (ketamine at $1-2 \mathrm{mg} / \mathrm{kg}$ ) plus sedative (midazolam at $0.05-0.1 \mathrm{mg} / \mathrm{kg}$ ) were routinely given intravenously to children aged 10 years or younger, undergoing PRB, whereas patients over 10 years of age were prescribed only local anesthesia (1-2\% xylocaine). In some cases, eperidine was given intramuscularly to those children who feared pain. Fasting for four to six hours was recommended to reduce the risk of aspiration caused by vomiting. During the procedure, the patients were in a prone position. Both the puncture site and biopsy equipment were disinfected after locating the lower pole of the kidney by US. The same pediatric nephrologist executed RB using an automated 
18-gauge needle gun under direct US guidance. At least two passes were performed in each biopsy, and the renal tissues obtained were sent for routine histological studies including light microscopy (Hematoxylin and Eosin stain and Periodic acid-Schiff stain), immunofluorescence (e.g., C3, IgA, IgG, $\operatorname{IgM}$, and $\mathrm{C} 1 \mathrm{q}$ ), and electron microscopy.

\section{Post-biopsy care}

After PRB, the patients required bed rest and remained in the hospital overnight for close observation of the heart rate and blood pressure. The patients were restricted by lying down in the prone position, particularly in the first eight hours, and a $0.5 \mathrm{~kg}$ sandbag was placed on the puncture site to boost the compression. In addition to urinalysis, a hemogloblin concentration test and follow-up US were arranged for the next day. If patients remained hemodynamically stable and did not experience unbearable discomfort or major bleeding complications, they were safely discharged and visited the Outpatient Department within one week after discharge. We also advised limited physical activity during this period.

\section{Statistical analysis}

The statistical data were analyzed by the Student's two-tailed $t$-test, Pearson's correlation coefficients, and the non-parametric test using the SPSS version 19.0. $p<0.05$ was considered to be significant.

\section{RESULTS}

The mean number of glomeruli obtained per biopsy was $19 \pm 10$, and at least two passes were practiced in each PRB. Adequate renal tissue for histological diagnosis was achieved in $99 \%$ of the cases except for one, which had insufficient glomeruli $(<5)$. As shown in Table 2, $3.0 \%$ (3/99) of the children developed transient gross hematuria following PRBs, and 11.1\% (11/99) had perirenal hematoma. Some patients complained of temporary flank pain after the eight-hour compression from using a sand bag placed on the puncture site. None of patients encountered major bleeding complications requiring medical intervention, such as blood transfusion, angiography embolization, emergent nephroectomy, or any sedation-related complications. These minor bleeding complications resolved spontaneously between the two-week and three-month follow-ups. Furthermore, the occurrence of biopsy-related bleeding complications was not related to age, gender, or the underlying kidney disease [Table 2]. In Table 1, it is shown that systemic lupus erythematosus (SLE) with renal involvement was the most frequent indication of renal biopsy $(35.2 \%, 32 / 91)$ for both male and female pediatric patients; $13.2 \%$ (12/91) and 3.3\% (3/91) of the PRBs were
Table 2: Comparisons of 99 biopsies performed in 91 children with and without the bleeding complication

\begin{tabular}{lccc}
\hline & $\begin{array}{c}(+) \text { Bleeding } \\
\text { complications } \\
\text { after RB } n=14\end{array}$ & $\begin{array}{c}(-) \text { Bleeding } \\
\text { complications } \\
\text { after RB } n=85\end{array}$ & Significant* \\
\hline Gender & $\mathrm{M}: \mathrm{F}=8: 6$ & $\mathrm{M}: \mathrm{F}=45: 40$ & $\mathrm{NS}$ \\
Age (years) & $8.77 \pm 5.81$ & $11.27 \pm 4.23$ & $\mathrm{NS}$ \\
Number of glomeruli & $17.2 \pm 9.9$ & $19.8 \pm 10.3$ & NS \\
obtained per biopsy & & & \\
Underlying renal & & & NS \\
disease & & & \\
Cystic kidney disease & 1 & & \\
FSGS & $1^{\dagger}$ & & \\
IgAN & 3 & & \\
LN & 4 & & \\
MCD & $2^{\ddagger}$ & & \\
Congenital NS & 1 & & \\
MPGN & 1 & & \\
PSGN & $1^{\ddagger}$ & & \\
\end{tabular}

*NS not significant, $p>0.05$; ${ }^{\dagger}$ Three cases (1 FSGS, 1 PSGN, and $1 \mathrm{MCD}$ ) suffered transient gross hematuria and 11 were found with perirenal hematoma after renal biopsy. Abbreviations: FSGS: Focal segmental glomerulonephritis; IgAN: IgA nephropathy; LN: Lupus nephritis; MCD: Minimal change disease; MPGN: Mesangial proliferative glomerulonephritis; PSGN: Post-streptococcal glomerulonephritis

performed on children who presented with Frequent-Relapsing Steroid-Dependent Nephrotic Syndrome (FRSDNS) and Steroid-Resistant Nephrotic Syndrome (SRNS). Besides, $13.2 \%$ (12/91) of the nephrotic pediatric patients, whose age was less than one year or over 10 years, underwent PRBs due to a poor response to corticosteroid treatment within the initial six weeks. This was because there is a likelihood of Focal Segmental Glomerulonephritis (FSGS) or Mesangial Proliferative Glomerulonephritis (MPGN), which have poor prognosis compared to Minimal Change Disease (MCD). Children with persistent asymptomatic hematuria ( $\geq 20 \mathrm{RBC} / \mathrm{uL}$ in urine) were advised to receive kidney biopsies for disease determination, especially if mild or moderate proteinuria $(100-500 \mathrm{mg} / \mathrm{dL})$ was coexisting $(24.2 \%, 22 / 91)$. Also, 9.9\% (9/91) of the PRBs were performed in patients who had unexplained renal failure.

Table 3 shows that LN (35.1\%), particularly World Health Organization (WHO) class IV (23.0\%), $\operatorname{MCD}(22.0 \%)$, and $\operatorname{IgAN}(13.2 \%)$, were the major kidney diseases in pediatric patients diagnosed with SLE, nephrotic syndrome, and persistent asymptomatic hematuria with or without mild-to-moderate proteinuria.

\section{DISCUSSION}

Serum creatinine and proteinuria are the conventional biomarkers used to diagnose kidney disease, but some limitations restrict their clinical use. Scr is not raised until renal injury is well-established, which delays the identi- 
Table 3: Histopathological diagnosis of 91 biopsied pediatric patients

\begin{tabular}{lc}
\hline & Cases $(\%)$ \\
\hline Primary glomerular disease & \\
Nephrotic syndrome & \\
MCD & $20(22.0)$ \\
FSGS & $4(4.4)$ \\
IgM nephropathy & $1(1.1)$ \\
Mesangial proliferation & $1(1.1)$ \\
Congenital nephrotic syndrome & $1(1.1)$ \\
IgA nephropathy & $12(13.2)$ \\
Mesangioproliferative GN & $1(1.1)$ \\
Post-streptococcal GN & $5(5.5)$ \\
Crescentic GN & $2(2.2)$ \\
Glomerulosclerosis & $1(1.1)$ \\
Minor glomerular abnormalities & $1(1.1)$ \\
Secondary glomerular disease & \\
Lupus nephritis & \\
WHO class I & $1(1.1)$ \\
WHO class II & $4(4.4)$ \\
WHO class III & $3(3.3)$ \\
WHO class IV & $21(23.0)$ \\
WHO class V & $2(2.2)$ \\
WHO class VI & $1(1.1)$ \\
Henoch-Schönlen Purpura (HSP) nephritis & $2(2.2)$ \\
ANCA vasculitis & $1(1.1)$ \\
Hereditary and congenital disease & \\
Alport syndrome & $1(1.1)$ \\
Thin basement membrane disease & $1(1.1)$ \\
Cystic kidney disease & $1(1.1)$ \\
Aubulointerstitial nephritis & $2(2.2)$ \\
Unclassified & $1(1.1)$ \\
Total & $1(1.1)$ \\
Abbrevichio acid nephropathy & $91(100)$ \\
\hline
\end{tabular}

Abbreviations: MCD: Minimal change disease; FSGS: Focal segmental glomerulonephritis; GN: Glomerulonephritis

fication of the disease. Although the level of proteinuria has good correlation with the degree of kidney damage, it is impossible to discriminate it from acute inflammation, which will respond to steroid or immunosuppressive treatment to chronic irreversible fibrosis. Hence, thus far RB has been the standard method for assessing patients with kidney disease. In comparison to Scr and proteinuria, RB is an invasive examination. Nevertheless, the introduction of real-time US-guided PRB and automated biopsy guns significantly improve the diagnostic accuracy and reduce the risk of biopsy-related complications as well. The overall complication rate of inpatient PRBs in children was around $5.2 \sim 23.5 \%$, whereas the complication rate of outpatient PRBs was $2.6 \sim 11.4 \%$. The lower complication rate of outpatient PRBs might be due to underestimation. Although some suggested that pediatric outpatient RBs were practical in terms of cost savings, ${ }^{[9,12-14]}$ the optimal time for bed rest and in-hospital observation after biopsy remains contro- versial. Previous studies reported that a minimum of six to twelve hours of observation was required to detect major bleeding complications. For renal function impairment patients, a longer 23- to 24-hour observation was advised, as they were in danger of bleeding post PRB. ${ }^{[15,16]}$

In addition to pre-biopsy fasting, we routinely prescribed general anesthesia, a combination of ketamine and sedatives, for children aged 10 years or younger, whereas, a local anesthetic was used for children greater than 10 years of age. Besides, an 18-gauge needle was adopted in all pediatric PRBs. Even though a 16-guage needle was considered to have good diagnostic yield, the higher rate of bleeding complications were a concern. ${ }^{[6]}$ Compared to the use of a 16-guage needle, our result showed that an 18-gauge biopsy needle had similar efficiency and was much safer.

Since August 1990, mass urinary screening has been executed in elementary and junior high-school students in Taiwan. Many children have been taken to hospital for further evaluation if abnormal urinalysis persisted. For those who presented with heavy proteinuria, renal function deterioration, or renal involvement as part of a systemic or autoimmune disorder, RB was a clear-cut indication for disease identification. However, the consideration and optimal timing of RB in children with persistent asymptomatic isolated microscopic hematuria are inconclusive.

As the matter of fact, hematuria is not an uncommon finding of routine urinalysis in children. Murakami $\mathrm{M}$ et al. conducted a 13-year cross-sectional study to determine the prevalence of asymptomatic urine abnormalities in school children aged six to fourteen years in Japan. ${ }^{[17]}$ Their data suggested that the prevalence of asymptomatic hematuria (6-20 RBC/HPF) in elementary and junior-high school students was 0.37 and $0.94 \%$, respectively, whereas, the prevalence of proteinuria in elementary and junior-high school students was 0.08 and $0.54 \%$, respectively. Furthermore, it was reported that $9.3 \%$ of Japanese school children presented with hematuria $\left(\geq 6 \mathrm{RBC} / \mathrm{mm}^{3}\right.$ in uncentrifuged urine) ${ }^{[18]}$ In Taiwan, Lin et al., analyzed 513 school children, who were identified with various gradings of persistent urine abnormalities [microscopic hematuria only, light proteinuria $(30-100 \mathrm{mg} / \mathrm{dl})$, combined with microscopic hematuria and light proteinuria, and heavy proteinuria $(>100 \mathrm{mg} / \mathrm{dl})]^{\left[{ }^{[19]}\right.}$ In their study, it showed that $46.4 \%$ had persistent isolated microhematuria, and $14.3 \%$ had persistent microhematuria with associated light proteinuria. The remaining 39.3\% had proteinuria. SLE with renal involvement was the major secondary GN, and severe form of LN could occur in children with persistent microscopic hematuria, but without proteinuria. Also, their result suggested that IgAN and other nephritis had an important role to play in children who had persistent isolated hematuria as well as those who had co-existing proteinuria. 
Similarly, our study showed that regardless of gender, LN was the principal cause leading to childhood renal disease. With a poor link between clinical presentation, urinalysis, and the pathohistological patterns of LN, RB becomes the standard examination for the early diagnosis of severe LN. Moreover, for patients who are more than 10 years old and have severe renal disease underlined with SRNS, FRSDNS, and NS, RB is indicated. As a result, only one case of FRSDNS was diagnosed with FSGS. MCD remains the leading cause of childhood nephrotic syndrome.

In the present study, PRBs were performed on 22 children with persistent asymptomatic hematuria. As shown in Tables 4 and 5, 12 (54.5\%) were confirmed with IgAN. Among these patients, four of them (No. 3, 8, 9, 12) clinically presented with persistent asymptomatic isolated hematuria, and the majority had minor glomerular abnormality at diagnosis, except one case (No. 9). Looking at the patient (No. 11), this boy received a repeat biopsy at the remission stage after one-year, combined glucocorticosteroid and cyclophosphamide treatment. Despite clinical stabilization and only microscopic hematuria seen in urinalysis, there was no remarkable histological improvement in his kidneys.

Several literatures have shown that IgAN is the common primary etiology underlying children who have persistent microscopic hematuria, with or without associated proteinuria. ${ }^{[17-20]}$ Moreover, proteinuria over $0.5 \mathrm{~g} /$ day is suggested as a late manifestation in IgAN. ${ }^{[21,22]}$ The latest nationwide, population-based retrospective cohort study was conducted to assess the long-term outcome of adolescents and young adults with persistent asymptomatic isolated microscopic hematuria, in Israel. ${ }^{[23]}$ During the almost 22-year follow-up, they had found that there was a remarkably higher incidence of patients treated for end-stage renal disease (ESRD) as opposed to patients without persistent asymptomatic isolated microscopic hematuria, 34.0 and 2.05 per million people, respectively. Furthermore, primary GN, including IgAN, was attributed to more than $50 \%$ of these ESRD patients. Their fundamental finding suggested that persistent asymptomatic isolated microscopic hematuria among young people can be a marker of predicting progressive kidney disease. This emphasizes the significance of the early detection of unknown renal disease, before the nephritic symptoms and signs are seen. As clinical features and laboratory examination are not adequate enough to make the diagnosis of either IgAN or subtypes of LN, RB is believed as the most trustworthy method for identifying the disease at an early stage.

It is known that there is a higher prevalence and incidence of ESRD in Taiwan. In addition to the potential

Table 4: Demographic characteristics of 12 persistently hematuric pediatric patients who were diagnosed with IgAN

\begin{tabular}{|c|c|c|c|c|c|c|}
\hline $\begin{array}{l}\text { Patient } \\
\text { no. }\end{array}$ & Gender & Age & Clinical presentations & $\begin{array}{c}\text { Proteinuria at } \\
\text { diagnosis (g/day) }\end{array}$ & $\begin{array}{l}\text { IgAN subtypes } \\
*\end{array}$ & $\begin{array}{l}\text { Follow-up duration } \\
\text { before renal biopsy }\end{array}$ \\
\hline 1 & Female & $\begin{array}{l}13 \text { years } \\
6 \text { months }\end{array}$ & $\begin{array}{l}\text { Nephrotic syndrome, history of } \\
\text { persistent microscopic hematuria }\end{array}$ & 10.13 & IgAN IV & 7 days \\
\hline 2 & Male & $\begin{array}{l}15 \text { years } \\
3 \text { months }\end{array}$ & $\begin{array}{l}\text { History of persistent microscopic } \\
\text { hematuria, hypertension }\end{array}$ & 1.24 & $\operatorname{IgAN} I$ & 15 days \\
\hline 3 & Female & $\begin{array}{l}9 \text { years } \\
3 \text { months }\end{array}$ & $\begin{array}{l}\text { Persistent asymptomatic } \\
\text { microscopic hematuria }\end{array}$ & 0.39 & $\operatorname{IgAN} I$ & 1.7 years \\
\hline 4 & Female & $\begin{array}{l}10 \text { years } \\
11 \text { months }\end{array}$ & Persistent microscopic hematuria & 1.34 & $\operatorname{IgAN} I$ & 7 years \\
\hline 5 & Male & 10 years & $\begin{array}{l}\text { Persistent micro- and macroscopic } \\
\text { hematuria }\end{array}$ & 3.24 & IgAN III & 2 months \\
\hline 6 & Male & $\begin{array}{l}15 \text { years } \\
8 \text { months }\end{array}$ & $\begin{array}{l}\text { Persistent microscopic hematuria, } \\
\text { renal function impairment }\end{array}$ & 8.08 & IgAN V (ESRD) & 7 years \\
\hline 7 & Female & $\begin{array}{l}14 \text { years } \\
9 \text { months }\end{array}$ & $\begin{array}{l}\text { Persistent asymptomatic } \\
\text { microhematuria }\end{array}$ & 2.0 & IgAN IV & 2.5 years \\
\hline 8 & Male & 6 years & $\begin{array}{l}\text { Persistent asymptomatic } \\
\text { micro- and macroscopic hematuria }\end{array}$ & 0.32 & $\operatorname{IgAN} I$ & 1.3 years \\
\hline 9 & Male & 7 years & $\begin{array}{l}\text { Persistent asymptomatic } \\
\text { micro- and macroscopic hematuria }\end{array}$ & 0.13 & IgA N IV & 3 months \\
\hline 10 & Male & $\begin{array}{l}6 \text { years } \\
3 \text { months }\end{array}$ & $\begin{array}{l}\text { History of persistent asymptomatic } \\
\text { micro- and macroscopic hematuria }\end{array}$ & 3.29 & IgAN III & 22 days \\
\hline \multirow[t]{2}{*}{11} & Male & 4 years & $\begin{array}{l}\text { Renal impairment, history of } \\
\text { persistent microscopic hematuria }\end{array}$ & 4.05 & $\begin{array}{l}\text { IgAN IV } \\
\text { (60\% crescents) }\end{array}$ & 9 days \\
\hline & & 5 years & $\begin{array}{l}\text { Normal renal function, } \\
\text { microscopic hematuria }\end{array}$ & 0.05 & $\begin{array}{l}\text { IgAN IV } \\
{ }^{\dagger}(60 \% \text { crescents })\end{array}$ & \\
\hline 12 & Female & $\begin{array}{l}12 \text { years } \\
3 \text { months }\end{array}$ & $\begin{array}{l}\text { Persistent asymptomatic } \\
\text { microscopic hematuria }\end{array}$ & 0.26 & IgAN I & 6 years \\
\hline
\end{tabular}


Table 5: The distribution of histological diagnosis among 22 children with persistent asymptomatic hematuria with and without mild-to-moderate proteinuria

\begin{tabular}{lcc}
\hline & \multicolumn{2}{c}{ Number of patients, $n=22(\%)$} \\
\cline { 2 - 3 } & $\begin{array}{c}\text { Persistent } \\
\text { isolated } \\
\text { hematuria }(n=4)\end{array}$ & $\begin{array}{c}\text { Persistent hematuria } \pm \\
\text { mild-to-moderate } \\
\text { proteinuria }(n=18)\end{array}$ \\
\hline IgA nephropathy & $4(18.18)$ & $8(36.36)$ \\
Tubulointerstitial nephritis & $2(9.09)$ \\
HSP nephritis & $2(9.09)$ \\
Thin basement membrane & $1(4.55)$ \\
disease & $1(4.55)$ \\
Mesangioproliferative GN & $1(4.55)$ \\
Alport syndrome & $1(4.55)$ \\
Cystic kidney disease & $2(9.09)$ \\
Minor glomerular & \\
abnormalities or & \\
unclassified & \\
\hline
\end{tabular}

risk factors (e.g., hypertension, diabetes, and use of illegal Chinese herbs), the attribution of primary GN, such as, IgAN to ESRD, to patients with unknown etiologies is unclear, and it is probably underestimated due to the delay of diagnosis. Without prompt therapeutic intervention, uninterrupted subtle inflammation can begin in IgAN children, which will result in irreversible renal fibrosis in adulthood. Therefore, even though there is no need for intensive medication at the early stage of the disease, children and their parents can benefit from more medical advice and support throughout the subsequently longstanding follow-up.

However, there are some limitations to this study. The number of children with persistently asymptomatic hematuria is small and a longer observation is also required to ascertain the benefit of ameliorating long-term renal survival.

\section{Conclusion}

Real time US-guided PRB with a biopsy gun is a safe and effective examination in children with kidney disease. Our result showed that $\mathrm{LN}, \mathrm{MCD}$, and IgAN were the most common childhood kidney diseases in Taiwan. In the study, it also highlighted that IgAN is an important cause of primary glomerular disease in children who present with persistent asymptomatic hematuria, with and without associated proteinuria. As persistent asymptomatic microscopic hematuria was suggested as a poor renal prognostic indicator, RB should be emphasized for early detection of asymptomatic patients, who are at risk of progressive renal disease.

\section{REFERENCES}

1. Feneberg R, Schaefer F, Zieger B, Waldherr R, Mehls O, Scharer K. Percutaneous renal biopsy in children: A 27 -year experience. Nephron 1998;79:438-46.
2. Kamitsuji H, Yoshioka K, Ito H. Percutaneous renal biopsy in children: Survey of pediatric nephrologists in Japan. Pediatr Nephrol 1999;13:693-6.

3. Kersnik Levart T, Kenig A, Buturovic Ponikvar J, Ferluga D, Avgustin Cavic M, Kenda RB. Real-time ultrasound-guided renal biopsy with a biopsy gun in children: Safety and efficacy. Acta Paediatr 2001;90:1394-7.

4. Maya ID, Maddela P, Barker J, Allon M. Percutaneous renal biopsy: Comparison of blind and real-time ultrasound-guided technique. Semin Dial 2007;20:355-8.

5. Demircin G, Delibas A, Bek K, Erdogan O, Bulbul M, Baysun S, et al. A one-center experience with pediatric percutaneous renal biopsy and histopathology in Ankara, Turkey. Int Urol Nephrol 2009;41:933-9.

6. Piotto GH, Moraes MC, Malheiros DM, Saldanha LB, Koch VH. Percutaneous ultrasound-guided renal biopsy in children-safety, efficacy, indications and renal pathology findings: 14-year Brazilian university hospital experience. Clin Nephrol 2008;69:417-24.

7. Sinha MD, Lewis MA, Bradbury MG, Webb NJ. Percutaneous real-time ultrasound-guided renal biopsy by automated biopsy gun in children: Safety and complications. J Nephrol 2006;19:41-4.

8. Skalova S, Rejtar P. Safety profile of paediatric percutaneous ultrasonography-guided renal biopsies. Singapore Med J 2010;51:481-3.

9. Al Makdama A, Al-Akash S. Safety of percutaneous renal biopsy as an outpatient procedure in pediatric patients. Ann Saudi Med $2006 ; 26: 303-5$

10. al Rasheed SA, al Mugeiren MM, Abdurrahman MB, Elidrissy AT. The outcome of percutaneous renal biopsy in children: An analysis of 120 consecutive cases. Pediatr Nephrol 1990;4:600-3.

11. Gauthier BG, Mahadeo RS, Trachtman H. Techniques for percutaneous renal biopsies. Pediatr Nephrol 1993;7:457-63.

12. Ogborn MR, Grimm PC. Pediatric renal biopsy in the ambulatory care environment. Pediatr Nephrol 1992;6:311-2.

13. Simckes AM, Blowey DL, Gyves KM, Alon US. Success and safety of same-day kidney biopsy in children and adolescents. Pediatr Nephrol 2000;14:946-52.

14. Sweeney C, Geary DF, Hebert D, Robinson L, Langlois V. Outpatient pediatric renal transplant biopsy--is it safe? Pediatr Transplant 2006;10:159-61.

15. Marwah DS, Korbet SM. Timing of complications in percutaneous renal biopsy: What is the optimal period of observation? Am J Kidney Dis 1996;28:47-52.

16. Whittier WL, Korbet SM. Timing of complications in percutaneous renal biopsy. J Am Soc Nephrol 2004;15:142-7.

17. Murakami M, Yamamoto H, Ueda Y, Murakami K, Yamauchi K. Urinary screening of elementary and junior high-school children over a 13-year period in Tokyo. Pediatr Nephrol 1991;5:50-3.

18. Vehaskari VM, Rapola J, Koskimies O, Savilahti E, Vilska J, Hallman N. Microscopic hematuria in school children: Epidemiology and clinicopathologic evaluation. J Pediatr 1979;95:676-84.

19. Lin CY, Hsieh CC, Chen WP, Yang LY, Wang HH. The underlying diseases and follow-up in Taiwanese children screened by urinalysis. Pediatr Nephrol 2001;16:232-7.

20. Park YH, Choi JY, Chung HS, Koo JW, Kim SY, Namgoong MK, et al. Hematuria and proteinuria in a mass school urine screening test. Pediatr Nephrol 2005;20:1126-30. 
21. Kincaid-Smith P, Nicholls K. Mesangial IgA nephropathy. Am J Kidney Dis 1983;3:90-102.

22. Kobayashi Y, Tateno S, Hiki Y, Shigematsu H. IgA nephropathy: Prognostic significance of proteinuria. Nephron 1983;34:146-53.
23. Vivante A, Afek A, Frenkel-Nir Y, Tzur D, Farfel A, Golan E, et al. Persistent asymptomatic isolated microscopic hematuria in Israeli adolescents and young adults and risk for end-stage renal disease. JAMA 2011;306:729-36. 